\title{
BMJ Open Prognostic factors of carbon monoxide poisoning in Taiwan: a retrospective observational study
}

\author{
Ke-Ting Pan (D) , ${ }^{1,2}$ Chih-Hao Shen, ${ }^{3}$ Fu-Gong Lin, ${ }^{4}$ Yu-Ching Chou, ${ }^{4}$ \\ Ben Croxford, ${ }^{1}$ Giovanni Leonardi, ${ }^{5}$ Kun-Lun Huang ${ }^{2,3}$
}

To cite: Pan K-T, Shen C-H, $\mathrm{Lin} \mathrm{F}-\mathrm{G}$, et al. Prognostic factors of carbon monoxide poisoning in Taiwan: a retrospective observational study. BMJ Open 2019;9:e031135. doi:10.1136/ bmjopen-2019-031135

- Prepublication history for this paper is available online To view these files, please visit the journal online (http://dx.doi. org/10.1136/bmjopen-2019031135).

Received 17 April 2019 Revised 18 September 2019 Accepted 19 September 2019

Check for updates

(c) Author(s) (or their employer(s)) 2019. Re-use permitted under CC BY-NC. No commercial re-use. See rights and permissions. Published by BMJ.

${ }^{1}$ Bartlett School of Environment, Energy and Resources, University College London, London, UK

${ }^{2}$ Graduate Institute of Aerospace and Undersea Medicine, National Defense Medical Center, Taipei, Taiwan

${ }^{3}$ Division of Pulmonary and Critical Care Medicine, Department of Internal Medicine, Tri-Service General Hospital,

Taipei, Taiwan

${ }^{4}$ School of Public Health, National Defense Medical Center, Taipei, Taiwan

${ }^{5}$ Centre for Radiation, Chemical and Environmental Hazards, Public Health England, Didcot, UK

Correspondence to

Dr Kun-Lun Huang;

kun@ndmctsgh.edu.tw

\section{ABSTRACT}

Objectives To identify the risk factors related to the prognosis of carbon monoxide (CO)-poisoned patients in the hospital.

Design Retrospective observational study.

Setting Tri-Service General Hospital, Taiwan.

Methods We conducted a review of the medical records of $669 \mathrm{CO}$-poisoned patients, who were admitted to the Department of Emergency, Tri-Service General Hospital, Taiwan, from 2009 to 2014. Demographic, clinical and laboratory data were collected for analysis. In the study, the end points for poor outcome were patients who either still had sequelae, were bedridden or died after treatment. The independent t-test, $\chi^{2}$ test and binary logistic regression were used to identify the association between the prognostic factors and the outcomes.

Results The logistic regression analysis confirmed that the Glasgow Coma Scale (GCS) score $(p=0.008)$ and blood urea nitrogen (BUN) $(p=0.002)$ were related to poor outcomes. Furthermore, the receiver operating characteristic (ROC) curve showed that the cut-off point of intubation days was 1.5 days (area under the ROC curve $[A U C]=0.793)$ for all patients and 2.5 days $(A U C=0.817)$ for patients with intubation when predicting poor outcomes. Conclusion We identified the factors that most strongly predict the prognosis of CO poisoning, including the GCS score, serum BUN and intubation days. Moreover, the number of hyperbaric oxygen treatments seems to have impact of the outcome.

\section{INTRODUCTION}

Carbon monoxide (CO) poisoning is a global health issue. In a study by Mott et al, 116703 people died from non-fire $\mathrm{CO}$ poisoning in the USA from 1968 to 1998 , with around 10 deaths per day. ${ }^{1}$ In an UK-based study, 2463 $\mathrm{CO}$ poisoning admissions were noted from 2001 to 2010 , most of which were preventable. $^{2}$ The incidents of $\mathrm{CO}$ poisoning usually have a higher rate in winter, because people tend to use heaters and close the windows when the weather is cold..$^{2-5}$ The causes of CO poisoning include defective heaters, fires, cooking appliances, the exhaust of vehicles, smoke, waterpipe smoking and so on. ${ }^{6-8}$ Besides accidental $\mathrm{CO}$ poisoning, the number

\section{Strengths and limitations of this study}

- Most biochemical factors were considered in the study.

- Most of the carbon monoxide (CO)-poisoned patients received the hyperbaric oxygen therapy in the hospital.

- The rate of recovery was similar to other studies.

- Some data missing of the patients transferred from other hospitals.

- Give the specific indications for clinical research work and clinical practice with $\mathrm{CO}$-poisoned patients.

of deliberate $\mathrm{CO}$ intoxications increased due to the increased suicide rate by facing higher stress in their lives now than the past. ${ }^{9}$ The suicide rate has increased in Taiwan from around 15 to 35 per 100000 for males and from 8 to 16 per 100000 for females from 1992 to 2006. Most of them used charcoal as the source of $\mathrm{CO} .^{1011}$

$\mathrm{CO}$ poisoning causes cellular hypoxia by reducing oxygen delivery to tissues and decreasing the dissociation of oxygen from haemoglobin $(\mathrm{Hb})$ to the cells. Energy depletion is the direct cause of CO-induced cell damage, as oxidative phosphorylation is suppressed when cytochrome a3 in the inner membrane of mitochondria is inhibited by CO. ${ }^{12}{ }^{13}$ The most vulnerable organs are the heart and the brain because of their high oxygen demand. The symptoms of acute $\mathrm{CO}$ poisoning are headache, fatigue, nausea, vomiting, convulsion and death. ${ }^{14} 15$ Although there are some discussions on the use of hyperbaric oxygen ( $\mathrm{HBO})$ therapy in treating $\mathrm{CO}$ poisoning, ${ }^{16}{ }^{17}$ it has been shown to enhance $\mathrm{CO}$ elimination and reverse cytochrome a3 inhibition, resulting in a lower severity of neurological sequelae after CO poisoning. ${ }^{18}$ The neuropsychological sequelae include neurological deficits, 
cognitive impairments and affective disorders, ${ }^{19}{ }^{20}$ which may cause a drastic impact on the quality of life.

The majority of patients with $\mathrm{CO}$ poisoning are around 25-45 years of age in Taiwan representing the most productive group in the society. ${ }^{10}{ }^{21}$ If the factors related to the prognosis were known, then more effective treatments could have been offered. Some predictive factors have been proposed, including hydrogen ion, serum lactate, myocardial injury, Glasgow Coma Scale (GCS) score, leucocytosis and troponin I (TnI). ${ }^{6} 1819$ 22-25 However, the clinical indications are still controversial for predicting the outcomes in patients with $\mathrm{CO}$ poisoning. ${ }^{26}$ In the present study, we tried to find factors for predicting the prognosis of $\mathrm{CO}$ poisoning and providing indications for further clinical research work.

\section{METHODS}

\section{Study design}

A retrospective observational study was conducted at the Hyperbaric Oxygen Therapy Centre, Tri-Service General Hospital, Taipei, Taiwan. Data were collected on all CO-poisoned patients admitted to the hospital and were coded with CO poisoning (International Classification of Diseases, Ninth Revision, Clinical Modification Diagnosis Code 986-Toxic Effect of Carbon Monoxide) from September 2009 to August 2014. There were 669 patients in the study and data were also retrieved from the medical records (paper and digital records) and online database of the hospital, including demographic data, clinical data and laboratory data. Patient data that were missing clinical information or laboratory information or did not have defined outcome information were excluded from the study.

\section{Data collection}

For patients included in the study, the following variables were collected and analysed: CO source; height; weight; body mass index (BMI); sex; suicide attempt; habits of smoking and drinking; chronic diseases of the patients, including psychosis, diabetes and hypertension; the initial GCS score on arriving at the emergency department (ED); times of $\mathrm{HBO}$ treatment for patients since they arrived at the ED; the number of days for which the patients were intubated, stayed in the intensive care unit (ICU) and were hospitalised; whether they used benzodiazepines (BZD) and also the clinical symptoms of poisoning, including metabolic acidosis, rhabdomyolysis and myocardial injury.

The initial laboratory data after they arrived at the ED in the Tri-Service General Hospital were recorded in the study, including the $\mathrm{COHb}$ level, arterial blood gas data, white blood cell (WBC) and platelet count, $\mathrm{Hb}$ level, creatine kinase (CK), creatine kinase-myocardial band (CKMB), TnI, serum levels of glucose, blood urea nitrogen (BUN), serum creatinine (Cre), aspartate aminotransferase (AST), alanine aminotransferase (ALT) and base excess (BE).

\section{Patient and public involvement}

Patients were involved in this study.

\section{Definition}

The clinical criteria were defined as follows: when a patient's BE was lower than $-2 \mathrm{mmol} / \mathrm{L}$, then the patient was assumed to be in metabolic acidosis; rhabdomyolysis was assumed in those who had CK $>5000$ units/L; patients who have CKMB $>25$ units/L and those with $\mathrm{TnI}$ of $>1.5$ $\mathrm{ng} / \mathrm{mL}$ were described to have myocardial injury.

Patients were separated into two groups (poor outcome and non-poor outcome). Patients in the poor-outcome group were those who either still had sequelae, were bedridden or died after treatment.

\section{Statistical analysis}

For the two groups in the study (ie, poor outcome and non-poor outcome), factors that may relate to the outcomes were analysed using the t-test for continuous variables (eg, age, height and concentration of CK) and $\chi^{2}$ test for categorical variables (eg, sex, psychosis and myocardial injury). A multivariate logistic regression model with adjusting variables was applied to find the factors that are related to the outcome. A $p$ value $<0.05$ was considered to be statistically significant, and all $\mathrm{p}$ values were two-sided. The IBM SPSS Statistics 24 statistical software (IBM, Armonk, New Y, USA) was used for data management and modelling.

\section{RESULT}

\section{Characteristics of the study group}

In the study, there were three different categories of CO poisoning: deliberate (336 patients), accidental firerelated (31 patients) and accidental non-fire-related (ANFR, 273 patients). The sources of $\mathrm{CO}$ poisoning in the ANFR case (29 patients had no data) were categorised into different types. The primary sources of CO poisoning in Taiwan were charcoal burning $(43,15.7 \%)$ and gas boilers or water heaters $(216,79.1 \%)$. These two sources accounted for $95 \%$ of the all CO poisoning cases, whereas car exhaust $(1,0.4 \%)$ and other factors (13, $4.8 \%$ ) accounted for $<10 \%$ of the data.

\section{Variables related to $\mathrm{CO}$ poisoning outcomes}

The variables related to the $\mathrm{CO}$ poisoning outcome of patients are shown in tables 1-3. Eighteen per cent of all patients (116 patients) were in the poor-outcome group. The mean age of all patients was $37.40 \pm 16.79$ years, with 46.7\% (269 patients) males and 53.3\% (338 patients) females. The category 'deliberate' accounted for around half of all patients. The percentages of chronic diseases in the patients were about $30 \%$ with psychosis, $6 \%$ with diabetes mellitus and $10 \%$ with hypertension. The key findings were as follows:

- Patients with poor outcomes were older than those who did not have poor outcomes $(\mathrm{p}<0.001)$. 
Table 1 Demographic characteristics related to the CO poisoning outcome

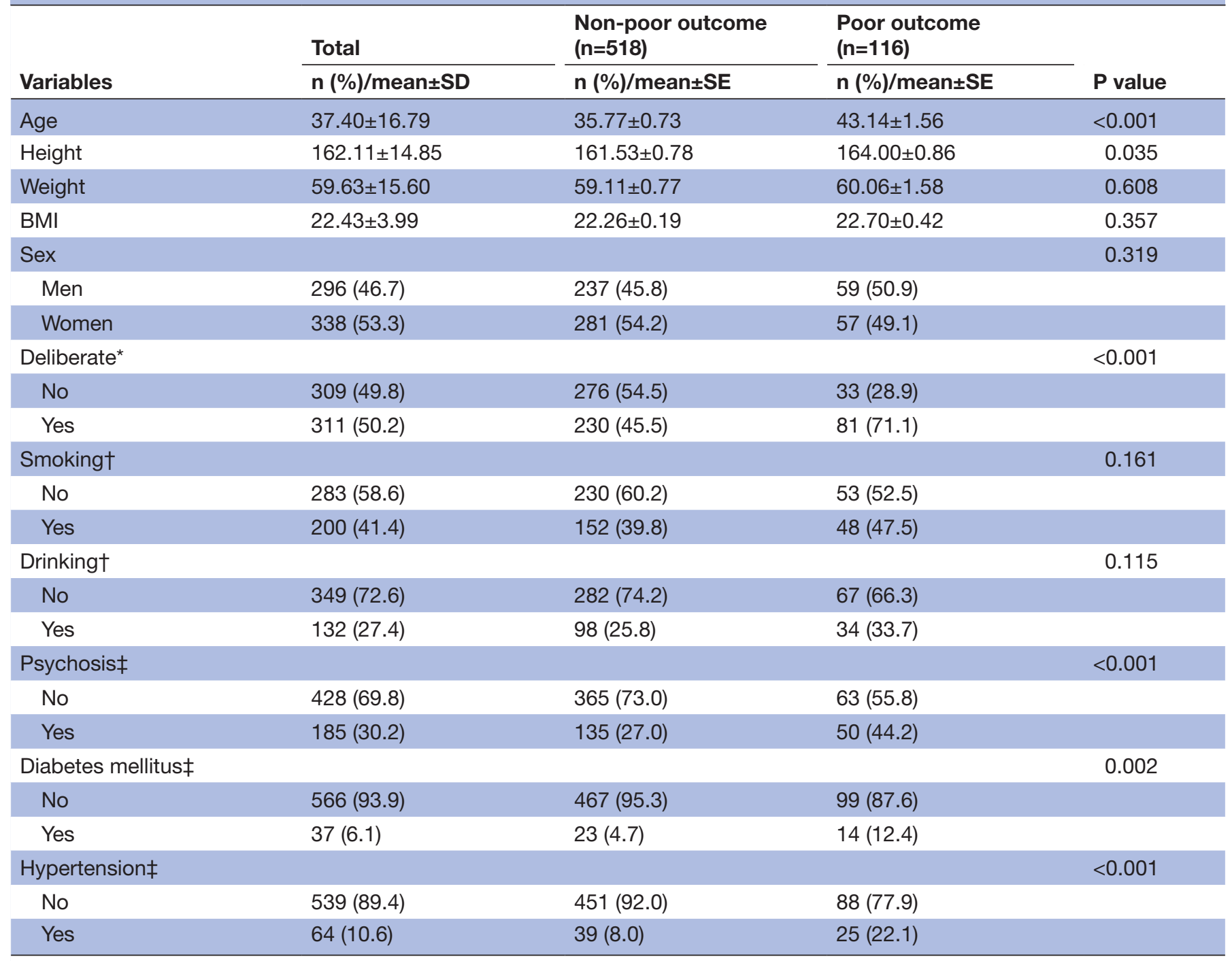

*Patients exposed to CO intentionally or by accident.

†Patients' habits.

‡Patients' chronic diseases.

$\mathrm{BMI}$, body mass index; $\mathrm{CO}$, carbon monoxide.

- Suicidal patients had a higher chance of poor outcomes compared with those who were exposed to CO by accident $(\mathrm{p}<0.001)$.

- Patients with rhabdomyolysis, myocardial injury and metabolic acidosis may be apt to have poor outcomes.

- Patients who had chronic diseases may tend to have poor outcomes.

- The patients' weight, BMI, gender and habits (smoking and drinking) had no significant correlation with the outcomes.

The clinical characteristics exhibited more significant results (table 2). The mean score of the GCS was around 11. The average number of $\mathrm{HBO}$ treatment sessions was about five for all patients. The percentages after exposure to $\mathrm{CO}$ were approximately $40 \%$ with metabolic acidosis, $8 \%$ with rhabdomyolysis and $21 \%$ with myocardial injury. In the poor-outcome group, the patients had a lower initial GCS score than those in the non-poor-outcome group $(\mathrm{p}<0.001)$. In the study, there were 646 patients who received $\mathrm{HBO}$ therapy, excluding those who did not receive $\mathrm{HBO}$ therapy or had missing data. The average number of $\mathrm{HBO}$ treatment sessions was around nine in the poor-outcome group and 3.5 in the non-poor-outcome group. The intubation days, the days for which the patient stayed in the ICU and the days of hospitalisation were greater in the poor-outcome group than in the non-poor-outcome group $(p<0.001)$. Moreover, $42 \%$ of the patients took BZD in the poor-outcome group compared with $22.3 \%$ in the non-poor-outcome group $(\mathrm{p}<0.001)$. When patients were exposed to $\mathrm{CO}$ and then suffered from metabolic acidosis, rhabdomyolysis or myocardial injury, they had a higher chance of a poor outcome $(\mathrm{p}<0.001)$. 
Table 2 Clinical characteristics related to CO poisoning outcomes

\begin{tabular}{|c|c|c|c|c|}
\hline & Total & $\begin{array}{l}\text { Non-poor outcome } \\
(\mathrm{n}=518)\end{array}$ & $\begin{array}{l}\text { Poor outcome } \\
(n=116)\end{array}$ & \\
\hline Variables & $\mathrm{n}(\%) /$ mean \pm SD & n (\%)/mean \pm SE & n (\%)/mean \pm SE & $P$ value \\
\hline GCS & $10.66 \pm 5.01$ & $11.5 \pm 0.21$ & $7.45 \pm 0.44$ & $<0.001$ \\
\hline HBO therapy sessions & $4.69 \pm 5.29$ & $3.50 \pm 0.16$ & $9.39 \pm 0.77$ & $<0.001$ \\
\hline Intubation days* & $2.22 \pm 8.64$ & $0.50 \pm 0.06$ & $10.08 \pm 1.78$ & $<0.001$ \\
\hline ICU days & $1.93 \pm 6.75$ & $0.59 \pm 0.06$ & $7.99 \pm 1.39$ & $<0.001$ \\
\hline Hospitalisation days & $6.91 \pm 16.92$ & $3.31 \pm 0.28$ & $22.84 \pm 3.17$ & $<0.001$ \\
\hline Metabolic acidosis $†$ & & & & $<0.001$ \\
\hline No & $353(59.4)$ & $307(63.4)$ & $46(41.8)$ & \\
\hline Yes & $241(40.6)$ & 177 (36.6) & $64(58.2)$ & \\
\hline BZD & & & & $<0.001$ \\
\hline No & $459(74.2)$ & $393(77.7)$ & $66(58.4)$ & \\
\hline Yes & $160(25.8)$ & $113(22.3)$ & $47(41.6)$ & \\
\hline Rhabdomyolysis $\ddagger$ & & & & $<0.001$ \\
\hline No & $550(91.5)$ & 463 (94.9) & $87(77.0)$ & \\
\hline Yes & $51(8.5)$ & $25(5.1)$ & $26(23.0)$ & \\
\hline Myocardial injury§ & & & & $<0.001$ \\
\hline No & $457(78.8)$ & $399(84.9)$ & $58(52.7)$ & \\
\hline Yes & $123(21.2)$ & $71(15.1)$ & $52(47.3)$ & \\
\hline
\end{tabular}

*Intubation days: days for which the patient underwent intubation.

†Metabolic acidosis:base excess $<-2 \mathrm{mmol} / \mathrm{L}$.

$\ddagger$ Rhabdomyolysis:creatine kinase $>5000 \mathrm{U} / \mathrm{L}$.

§Myocardial injury:creatine kinase-myocardialband $>25 \mathrm{U} / \mathrm{L}$ or troponin I $>1.5 \mathrm{ng} / \mathrm{mL}$.

BZD, benzodiazepines; CO, carbon monoxide; GCS, Glasgow Coma Scale; HBO, hyperbaric oxygen; ICU, intensive care unit.

Table 3 shows the laboratory data. With the exception of $\mathrm{Hb}$, platelets, the level of $\mathrm{pH}$ and plasma bicarbonate concentration $\left(\mathrm{HCO}_{3}-\right)$, all other variables exhibited abnormal values from the reference values. The concentration of WBCs, $\mathrm{Hb}$, platelets, $\mathrm{CKMB}$, the level of $\mathrm{pH}$ and the arterial oxygen tension $\left(\mathrm{PO}_{2}\right)$ showed no significant difference between the poor-outcome group and the non-poor-outcome group. Patients had a higher concentration of $\mathrm{CK}$ in the poor-outcome group than in the non-poor-outcome group $(\mathrm{p}=0.031$ in men, $\mathrm{p}<0.001$ in women). The concentrations of TnI, glucose, BUN, creatinine, AST and ALT were higher in the poor-outcome group than in the non-poor-outcome group. However, the pressure of arterial carbon dioxide tension $\left(\mathrm{PCO}_{2}\right)$, $\mathrm{HCO}_{3}{ }^{-}$, the concentration of $\mathrm{COHb}$ and $\mathrm{BE}$ were lower in the poor-outcome group than in the non-poor-outcome group.

Table 4 shows the variables that may predict the outcome of CO-poisoned patients after they underwent the HBO treatments. The variables in the model included psychosis, diabetes mellitus, metabolic acidosis, hypertension, GCS score, CK, TnI, glucose, BUN, Cre and AST. Age and sex were used as adjusting variables in the model. The OR of GCS was 0.932 (95\% CI 0.872 to 0.997$)$. When the patients had a higher score of GCS, they had a lower chance of having a poor outcome. The OR of BUN was
1.089 (95\% CI 1.031 to 1.150 ). If the patients had a higher concentration of BUN, they had a higher chance of having a poor outcome. The remaining variables in the model showed no statistically significant relationship with the outcomes.

\section{Intubation days and $\mathrm{CO}$ poisoning outcomes}

For cases of acute respiratory failure, patients' consciousness and haemodynamic variables were evaluated every hour. Ventilator management and weaning were performed by respiratory therapists according to the protocol of this hospital. Extubation criteria included stable haemodynamic variables, able to protect airway and spontaneously breathing for $30 \mathrm{~min}$ with reliable respiratory effort and oxygen saturation. Figures 1 and 2 show the receiver operating characteristic (ROC) curve of intubation days, including all patients (figure 1) and patients who were intubated (figure 2). The area under the ROC curve (AUC) was 0.757 for the intubation days of all patients (615 patients) and 0.817 for intubated patients (188 patients). The cut-off point was 1.5 intubation days in all patients and 2.5 intubation days in intubated patients. Therefore, for all patients, if their intubation days were $>1.5$ days, they may have a higher chance of having a poor outcome after treatment; for 
Table 3 Laboratory data related to CO poisoning outcomes

\begin{tabular}{|c|c|c|c|c|}
\hline & $\begin{array}{l}\text { Non-poor outcome } \\
(n=518)\end{array}$ & $\begin{array}{l}\begin{array}{l}\text { Poor } \\
\text { outcome } \\
(n=116)\end{array} \\
\end{array}$ & & \\
\hline Variables & Mean \pm SE & Mean \pm SE & $P$ value & Reference value \\
\hline WBC & $13.54 \pm 0.74$ & $15.06 \pm 0.58$ & 0.327 & $4.0-8.0$ \\
\hline \multicolumn{5}{|l|}{$\mathrm{Hb}$} \\
\hline Men & $148.71 \pm 1.07$ & $147.49 \pm 3.22$ & 0.649 & $135-176$ \\
\hline Women & $126.23 \pm 1.01$ & $127.70 \pm 2.72$ & 0.557 & $113-152$ \\
\hline Platelet ${ }^{\star}$ & $244.40 \pm 2.89$ & $242.44 \pm 7.39$ & 0.777 & $150.0-350.0$ \\
\hline \multicolumn{5}{|l|}{ CK } \\
\hline Men & $1121.20 \pm 212.91$ & $6231.71 \pm 2297.13$ & 0.031 & $57-197$ \\
\hline Women & $668.36 \pm 147.27$ & $2656.16 \pm 645.47$ & $<0.001$ & $32-180$ \\
\hline CKMB & $26.96 \pm 2.09$ & $35.09 \pm 3.29$ & 0.077 & $<25$ \\
\hline Tnl & $0.53 \pm 0.09$ & $2.90 \pm 0.78$ & 0.003 & $<0.5$ \\
\hline Glucose† & $128.14 \pm 2.44$ & $156.24 \pm 6.60$ & $<0.001$ & $70-110$ \\
\hline BUN & $15.09 \pm 0.33$ & $20.07 \pm 0.95$ & $<0.001$ & $9-21$ \\
\hline Cre & $0.89 \pm 0.02$ & $1.23 \pm 0.07$ & $<0.001$ & $0.2-0.9$ \\
\hline AST & $39.18 \pm 2.84$ & $140.81 \pm 26.26$ & $<0.001$ & $6-43$ \\
\hline ALT & $46.61 \pm 14.99$ & $228.25 \pm 72.84$ & 0.031 & $11-33$ \\
\hline $\mathrm{pH}$ & $7.40 \pm 0.003$ & $7.40 \pm 0.01$ & 0.556 & $7.40 \pm 0.07$ \\
\hline $\mathrm{PCO}_{2}$ & $37.75 \pm 0.37$ & $34.65 \pm 0.93$ & 0.002 & $40 \pm 4$ \\
\hline $\mathrm{PO}_{2}$ & $225.34 \pm 7.99$ & $256.37 \pm 15.67$ & 0.079 & $95 \pm 7$ \\
\hline $\mathrm{HCO}_{3}-$ & $22.88 \pm 0.18$ & $20.63 \pm 0.43$ & $<0.001$ & $24 \pm 2$ \\
\hline $\mathrm{COHb}$ & $12.52 \pm 0.18$ & $8.22 \pm 1.12$ & 0.001 & $<5$ \\
\hline $\mathrm{BE}$ & $-1.88 \pm 0.23$ & $-3.66 \pm 0.44$ & 0.001 & $0 \pm 2$ \\
\hline
\end{tabular}

${ }^{*}$ Platelet $\left(10^{3} / \mu \mathrm{L}\right)$.

†Glucose ( $\mathrm{mg} / \mathrm{dL})$.

ALT, alanine aminotransferase (U/L); AST, aspartate aminotransferase (U/L); BE, base excess (mmol/L); BUN, blood urea nitrogen ( $\mathrm{mg} / \mathrm{dL})$; $\mathrm{CK}$, creatine kinase (U/L); CKMB, creatine kinase-myocardial band (U/L); $\mathrm{CO}$, carbon monoxide; $\mathrm{COHb}, \mathrm{COHb}$ concentration (\%); Cre, serum creatinine (mg/dL); $\mathrm{Hb}$, haemoglobin ( $\mathrm{g} / \mathrm{dL}) ; \mathrm{HCO}_{3}-$, plasma bicarbonate concentration $(\mathrm{mmol} / \mathrm{L}) ; \mathrm{PCO}_{2}$, arterial carbon dioxide tension $(\mathrm{mm}$ $\mathrm{Hg})$; $\mathrm{pH}$, potential of hydrogen; $\mathrm{PO}_{2}$, arterial oxygen tension $(\mathrm{mm} \mathrm{Hg})$; Tnl, troponin I (mg/dL); WBC, white blood cell (103/ $\left./ \mathrm{LL}\right)$.

intubated patients, if their intubation days were $>2.5$ days, they may have a higher chance of having a poor outcome.

\section{DISCUSSION}

The epidemiology of $\mathrm{CO}$ poisoning differs from one country to another because of the weather, geographical and cultural variations. The main sources of $\mathrm{CO}$ poisoning in Taiwan are gas boilers or water heaters (accidental) and charcoal burning (intentional). The charcoal burning cases accounted for more than the half of the cases. The results were very different in Western countries. For example, the main sources of $\mathrm{CO}$ poisoning were heaters' and vehicles' exhaust in the UK and the USA. ${ }^{4} 2728$ Charcoal burning accounted for around 23\% of all suicides in Asia, a percentage that is 10 times higher than in Western countries. ${ }^{10}$ The mean age of patients in this study was 37.4 years. The age of CO-poisoned patients was around 40 years in Turkey, the USA and Italy. ${ }^{5} 1926$ The reason for the lower age in Taiwan may be the type of suicide prevalent in Taiwan. Recently, charcoal burning has become one of the main methods of suicide and has increased both in urban and in rural areas. ${ }^{10} 11$ Most of the suicides are in the group of young adults. An early prognostic factor evaluation is more important for this group of patients, because young adults may impose a heavier burden to their family and to the medical society if they have a worse neurological treatment outcome. Our data revealed that patients exposed to $\mathrm{CO}$ intentionally have a significantly worse treatment outcome than those by accident. This further stresses the importance of early diagnosis and management of this group of patients. Clinicians should refer patients who attempted suicide to psychiatrists to minimise the incidence of poor outcome.

The poor-outcome group in the study represented around $18 \%$ of the total. This treatment outcome was similar to those in the studies by Kao et al in Taiwan. ${ }^{22}$ In other countries, Weaver et al reported a poor treatment outcome of $25.0 \%$ in CO-poisoned patients treated with 
Table 4 Factors related to CO poisoning outcomes

\begin{tabular}{llll}
\hline \multirow{2}{*}{ Variable } & \multicolumn{2}{l}{ Model } & \\
\cline { 2 - 4 } & OR & $\mathbf{9 5 \%} \mathbf{C l}$ & P value \\
\hline Psychosis & 1.467 & 0.793 to 2.714 & 0.222 \\
Diabetes mellitus & 1.352 & 0.412 to 4.444 & 0.619 \\
Metabolic acidosis & 1.435 & 0.761 to 2.703 & 0.264 \\
\hline Hypertension & 1.285 & 0.491 to 3.362 & 0.609 \\
\hline GCS & $\mathbf{0 . 9 3 2}$ & $\mathbf{0 . 8 7 2}$ to 0.997 & $\mathbf{0 . 0 3 9}$ \\
CK & 1.000 & 1.000 to 1.000 & 0.685 \\
Tnl & 1.078 & 0.975 to 1.191 & 0.141 \\
Glucose & 1.000 & 0.995 to 1.005 & 0.989 \\
\hline BUN & $\mathbf{1 . 0 8 9}$ & $\mathbf{1 . 0 3 1}$ to $\mathbf{1 . 1 5 0}$ & $\mathbf{0 . 0 0 2}$ \\
Cre & 0.850 & 0.402 to 1.797 & 0.671 \\
\hline AST & 1.003 & 0.999 to 1.007 & 0.205 \\
\hline
\end{tabular}

Adjusting variables, age and sex.

AST, aspartate aminotransferase; BUN, blood urea nitrogen ; CK, creatine kinase; $\mathrm{CO}$, carbon monoxide; Cre, serum creatinine; GCS, Glasgow Coma Scale ; Tnl, troponin I.

$\mathrm{HBO}$ and of $46.1 \%$ in those with normobaric oxygen treatment alone. ${ }^{18}$ Pepe $e t$ al also found that 34 patients out of 141 (24\%) had delayed neuropsychological sequelae (DNS) after they left the hospital by 1 month. ${ }^{19}$ The better treatment outcome in Taiwan might be due to the high medical accessibility for $\mathrm{CO}$ poisoning in this

\section{ROC Curve}

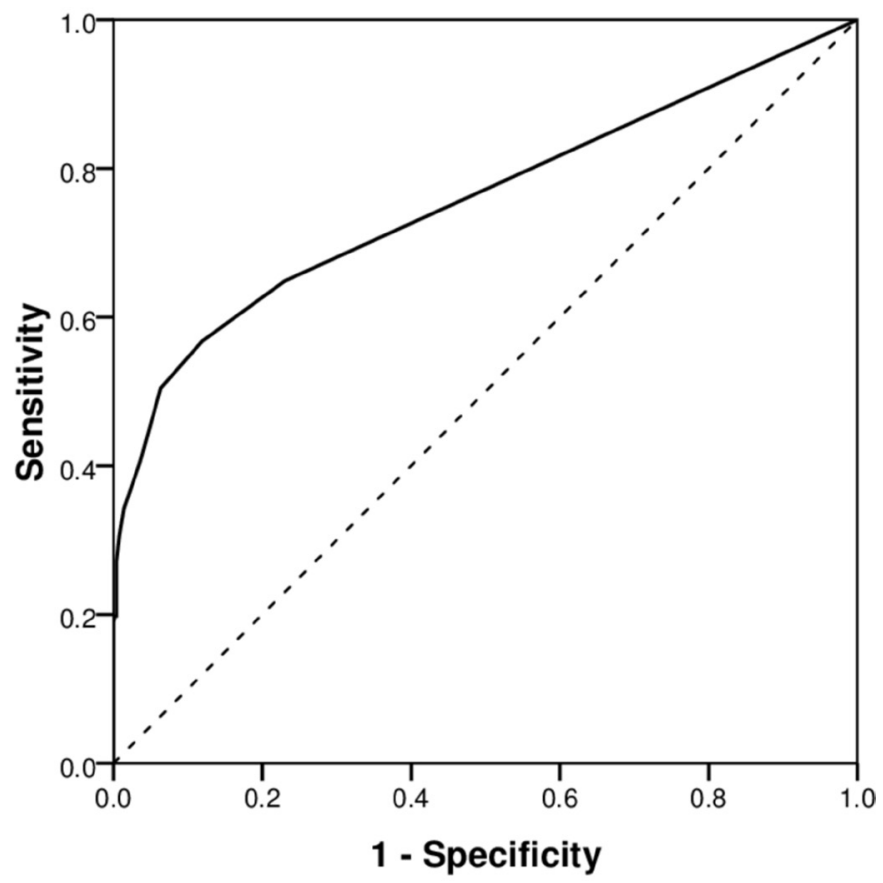

Diagonal segments are produced by ties.

Figure 1 Receiver operating characteristic (ROC) curves for the intubation days of all patients $(n=615)$.

\section{ROC Curve}

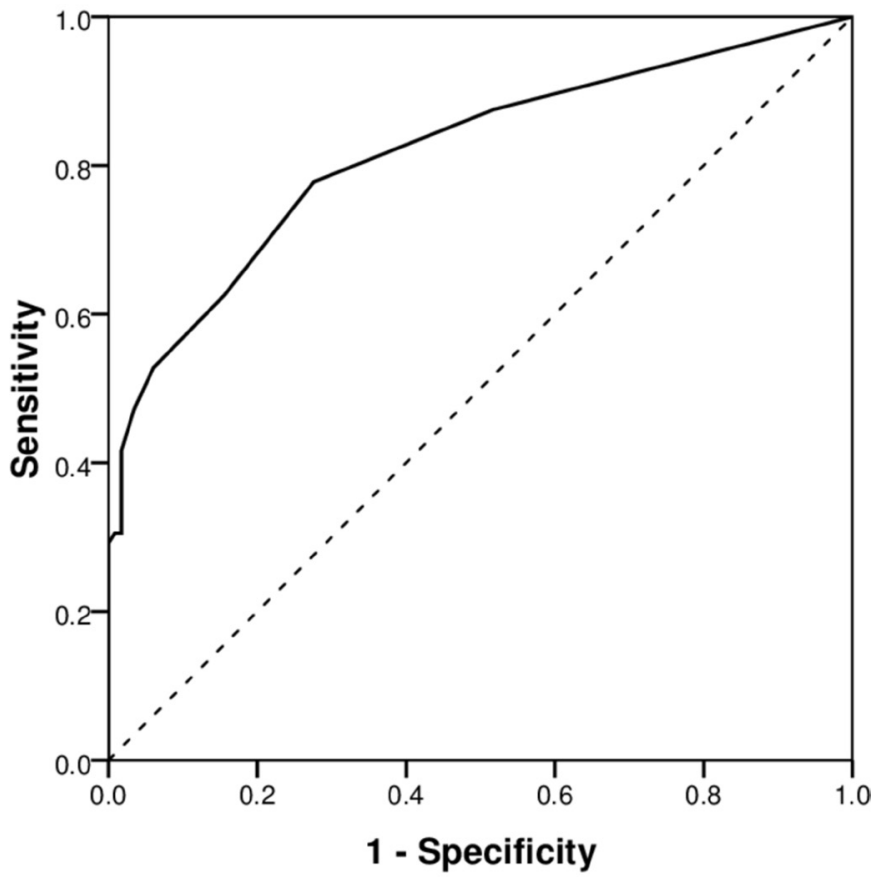

Diagonal segments are produced by ties.

Figure 2 Receiver operating characteristic (ROC) curves for the intubation days of patients with intubation treatment $(n=188)$.

country. Patients can reach hospitals with treatment facilities within 2 hours and the hospitals could quickly initiate HBO therapy or transfer to other treatment facilities in another 2 hours. Moreover, the treatment outcome in this study may be underestimated because of the high disease severity in our patients. This hospital is equipped with HBO therapy facilities for critically ill patients using ventilator and provides emergency treatments on an all year basis. Sixty per cent of our patients were transferred from other hospital for HBO therapy and $40 \%$ among them were using ventilator on arrival. For patients with such high severity, the treatment outcome could have been worse than it was analysed in this study. Certainly, other factors such as short duration of outcome assessment might also contribute to the lower incidence of poor outcome in this study. DNS usually occur around 20 days after poisoning. ${ }^{18}$ We evaluated the outcome based on the medical records that were available when the patients left the hospital or when they made return visits to the hospital 1 week later, so some patients may not have had later sequelae detected.

The GCS, an index of severity of neurological awareness, may be also an indicator of some injuries to other organs. An acute CO poisoning may severely suppress central drive of respiration, causing acute respiratory failure. However, a deeply comatous consciousness could be a consequence of overdose of sedatives, which happens frequently in patients attempting to suicide. 
The intubation days of patients, on the other hand, indicate their unconscious time and show the severity of the patients' illnesses. ${ }^{29}$ Our previous study also showed that the duration of mechanical ventilation is a predictor of $\mathrm{CO}$ poisoning severity. ${ }^{25}$ In this study, the intubation days were used as a predictor of the outcome of $\mathrm{CO}$ poisoning. The results show that the AUC was around $0.757-0.817$ in all patients and in intubated patients. Cha et al showed that GCS may be indicative of myocardial injury in CO-poisoned patients. ${ }^{30}$ Patients with a myocardial injury are usually more severely affected, so they may be more likely to have poor outcomes. ${ }^{31}{ }^{32}$ In this study, myocardial injury and GCS were closely related to the outcome of CO poisoning. These results are compatible with several other studies, ${ }^{19} 22233334$ suggesting that these two prognostic factors could be used to predict the treatment outcome of CO-poisoned patients. Some studies interpreted their results that people who suffered from a myocardial injury might have been exposed to $\mathrm{CO}$ longer than others. ${ }^{19} 303536$ However, there has been no report that could clearly identify the exposure duration. Our results showed that elevation of serum BUN in the first blood test is highly associated with poor outcome (table 4). For patients with a normal renal function, serum BUN could be a reliable indicator of body fluid status. Patients with $\mathrm{CO}$ poisoning cannot drink any water until the medical intervention, so the concentration of BUN may be related to the time between exposure to $\mathrm{CO}$ and presenting at the hospital. Therefore, elevation of BUN might be an indicator to predict the exposure time of $\mathrm{CO}$ poisoning and could be a predictor of poor treatment outcome.

In this study, almost all of the patients received $\mathrm{HBO}$ treatment. Patients were exposed to $100 \%$ oxygen at 3 atmospheres absolute for the first chamber session and then to $100 \%$ oxygen at 2.5 atmospheres absolute for the second and third chamber sessions. All chamber sessions consisted of three 25 min oxygen-breathing periods with two 5 min air breaks. Due to the fact that most of our patients were referred from other hospitals, their conditions were more severe and they were more in need of HBO treatment than in other local hospitals. In a recent study, Rose et al found that HBO treatment may reduce acute and 1-year mortality. ${ }^{26}$ They revealed that older age, being a male, respiratory distress and elevated TnI may relate to 1-year mortality, which could be considered as a poor outcome. Compared with the study by Rose $\mathrm{et} \mathrm{al}$, our results showed that all the above-mentioned factors, except gender, affect the outcome of CO-poisoned patients. It is interesting to note that in our study the poor outcome is associated with a more HBO therapy sections (table 2). In the regression analysis, the patients who received more HBO therapy sessions may have a higher opportunity to be poor outcome. This raise two concerns about the HBO therapy in CO-poisoned patients. First, could HBO therapy by itself cause poor outcome of CO poisoning? Patients in this study were initially treated with HBO therapy for three sessions. After the patient arrived our ED, the first hyperbaric chamber session was provided as soon as possible; and the third section was ideally to be performed $<24$ hours after the first chamber section. If it was possible, the interval between each section was around 6-12 hours. ${ }^{25}$ If the patients' conditions improved, the HBO therapy would stop; otherwise, they would receive more HBO therapy sections. Therefore, we would not interpret these data as that HBO therapy causes poor outcome of $\mathrm{CO}$ poisoning, but that patients need more sessions of HBO therapy had a higher disease severity. Second, is a multiple sections of HBO therapy necessary? The HBO therapy protocol adapted in this hospital was following the Undersea Hyperbaric Medical Society treatment indications of acute tissue injuries, such as crush injury, arterial insufficiency or thermal burn injury. In a nationwide population-based cohort study using Taiwan National Health Insurance Research Database (TNHIRD), Huang et al reported that CO-poisoned patients who received $\mathrm{HBO}$ therapy had a lower mortality rate $^{37}$ but a higher risk for neurological sequelae. ${ }^{38}$ It is interesting to note that the patient number in the without $\mathrm{HBO}$ therapy group was about 3 times of that in the HBO therapy group. In Taiwan, $\mathrm{CO}$ poisoning is a health insurance payable indication for HBO therapy and patients are supposed to receive HBO therapy in the hospital or be transferred to other treatment facilities, unless their disease severity did not fulfil treatment criteria. Therefore, the only explanation for lower risk of the without HBO therapy group is their lower severity of poisoning. Unfortunately, data from TNHIRD provide little information about disease severity of $\mathrm{CO}$ poisoning. In a small case series, Lo et al reported that 8-40 sections of HBO therapy significantly reduced the neurological and image abnormalities in CO-poisoned patients. ${ }^{39}$ Therefore, it remains unclear whether $\mathrm{HBO}$ therapy or multisection treatment will produce a better outcome than a conservative management.

Due to the fact that this study was retrospective in nature, there are some limitations. One is the incomplete data (eg, the total time of exposure to $\mathrm{CO}$, the initial $\mathrm{COHb}$ of patients, the time from exposure to presenting at the hospital and the duration of loss of consciousness), which may affect the outcomes of $\mathrm{CO}$ poisoning. Another limitation is that $>60 \%$ of the patients in this study were transferred from another hospital. This may result in a lack of the initial data, which were recorded in the previous hospital and ambulance.

\section{CONCLUSION}

In summary, in the present study, we tried to find the factors related to the poor prognosis of $\mathrm{CO}$ poisoning. The factors best at predicting outcomes were a high GCS score, high BUN and more intubation days. Even HBO therapy is paid by insurance in Taiwan, the benefit of repetitive $\mathrm{HBO}$ therapy on the treatment outcome remains to be elucidated. Our results in this retrospective study could give the indications for clinical research work in the future. 
Acknowledgements The authors would like to thank Dr Kao Li-Ting from National Defence Medical Centre for providing assistance in reviewing the manuscript and all the clinical staffs in Hyperbaric Oxygen Centre in Tri-Service General Hospital for their kind hospitality and for granting access to their medical records.

Contributors K-TP, C-HS and K-LH are responsible for the conception and design of the study. K-TP and C-HS collected data. K-TP, F-GL, Y-CC and K-LH analysed and interpreted data. K-TP and K-LH drafted the manuscript. K-TP, C-HS, BC, GL and K-LH discussed and approved the final version of the manuscript.

Funding The study was funded by Tri-Service General Hospital.

Competing interests None declared.

Patient consent for publication Not required.

Ethics approval This study was approved by the Institutional Review Board of the Tri-Service General Hospital (TSGHIRB Approval No. 2-101-05-034).

Provenance and peer review Not commissioned; externally peer reviewed.

Data availability statement № data are available.

Open access This is an open access article distributed in accordance with the Creative Commons Attribution Non Commercial (CC BY-NC 4.0) license, which permits others to distribute, remix, adapt, build upon this work non-commercially, and license their derivative works on different terms, provided the original work is properly cited, appropriate credit is given, any changes made indicated, and the use is non-commercial. See: http://creativecommons.org/licenses/by-nc/4.0/.

ORCID iD

Ke-Ting Pan http://orcid.org/0000-0003-0338-1083

\section{REFERENCES}

1 Mott JA, Wolfe MI, Alverson CJ, et al. National vehicle emissions policies and practices and declining us carbon monoxide-related mortality. JAMA 2002;288:988-95.

2 Ghosh RE, Close R, McCann LJ, et al. Analysis of hospital admissions due to accidental non-fire-related carbon monoxide poisoning in England, between 2001 and 2010. J Public Health 2016;38:76-83.

3 Clower JH, Hampson NB, Iqbal S, et al. Recipients of hyperbaric oxygen treatment for carbon monoxide poisoning and exposure circumstances. Am J Emerg Med 2012;30:846-51.

4 Hamilton-Farrell MR. British hyperbaric association carbon monoxide database, 1993-96. J Accid Emerg Med 1999;16:98-103.

5 lqbal S, Law H-Z, Clower JH, et al. Hospital burden of unintentional carbon monoxide poisoning in the United States, 2007. Am J Emerg Med 2012;30:657-64.

6 Turner M, Esaw M, Clark RJ. Carbon monoxide poisoning treated with hyperbaric oxygen: metabolic acidosis as a predictor of treatment requirements. J Accid Emerg Med 1999;16:96-8.

7 llano AL, Raffin TA. Management of carbon monoxide poisoning. Chest 1990;97:165-9.

8 Eichhorn L, Michaelis D, Kemmerer M, et al. Carbon monoxide poisoning from waterpipe smoking: a retrospective cohort study. Clin Toxicol 2018;56:264-72.

9 Tsai C-W, Gunnell D, Chou Y-H, et al. Why do people choose charcoal burning as a method of suicide? an interview based study of survivors in Taiwan. J Affect Disord 2011;131:402-7.

10 Chang S-S, Gunnell D, Wheeler BW, et al. The evolution of the epidemic of charcoal-burning suicide in Taiwan: a spatial and temporal analysis. PLoS Med 2010;7:e1000212.

11 Liu KY, Beautrais A, Caine E, et al. Charcoal burning suicides in Hong Kong and urban Taiwan: an illustration of the impact of a novel suicide method on overall regional rates. J Epidemiol Community Health 2007;61:248-53.

12 R Oliveira S, Queiroga CSF, Vieira HLA. Mitochondria and carbon monoxide: cytoprotection and control of cell metabolism - a role for $\mathrm{Ca}^{(2+)}$ ? J Physiol 2016;594:4131-8.

13 Queiroga CSF, Almeida AS, Vieira HLA. Carbon monoxide targeting mitochondria. Biochem Res Int 2012;2012:1-9.

14 Croxford B, Leonardi GS, Kreis I. Self-Reported neurological symptoms in relation to $\mathrm{CO}$ emissions due to problem gas appliance installations in London: a cross-sectional survey. Environ Health 2008;7.

15. Weaver LK. Clinical practice. carbon monoxide poisoning. $N$ Engl $J$ Med 2009;306:1217-25.

16 Annane D, Chadda K, Gajdos P, et al. Hyperbaric oxygen therapy for acute domestic carbon monoxide poisoning: two randomized controlled trials. Intensive Care Med 2011;37:486-92.

17 Buckley NA, Juurlink DN, Isbister G, et al. Hyperbaric oxygen for carbon monoxide poisoning. Cochrane Database Syst Rev 2011.

18 Weaver LK, Hopkins RO, Chan KJ, et al. Hyperbaric oxygen for acute carbon monoxide poisoning. N Engl J Med 2002;347:1057-67.

19 Pepe G, Castelli M, Nazerian P, et al. Delayed neuropsychological sequelae after carbon monoxide poisoning: predictive risk factors in the emergency department. A retrospective study. Scand J Trauma Resusc Emerg Med 2011;19:16.

20 Sykes OT, Walker E. The neurotoxicology of carbon monoxide Historical perspective and review. Cortex 2016;74:440-8.

21 Pan Y-J, Liao S-C, Lee M-B. Suicide by charcoal burning in Taiwan, 1995-2006. J Affect Disord 2010;120:254-7.

$22 \mathrm{Kao} \mathrm{H}-\mathrm{K}$, Lien T-C, Kou YR, et al. Assessment of myocardial injury in the emergency department independently predicts the short-term poor outcome in patients with severe carbon monoxide poisoning receiving mechanical ventilation and hyperbaric oxygen therapy. Pulm Pharmacol Ther 2009;22:473-7.

23 Grieb G, Simons D, Schmitz L, et al. Glasgow coma scale and laboratory markers are superior to $\mathrm{COHb}$ in predicting $\mathrm{CO}$ intoxication severity. Burns 2011;37:610-5.

24 Benaissa ML, Mégarbane B, Borron SW, et al. Is elevated plasma lactate a useful marker in the evaluation of pure carbon monoxide poisoning? Intensive Care Med 2003;29:1372-5.

25 Shen $\mathrm{C}-\mathrm{H}$, Peng C-K, Chou Y-C, et al. Predicting duration of mechanical ventilation in patients with carbon monoxide poisoning: a retrospective study. J Crit Care 2015;30:19-24.

26 Rose JJ, Nouraie M, Gauthier MC, et al. Clinical outcomes and mortality impact of hyperbaric oxygen therapy in patients with carbon monoxide poisoning. Crit Care Med 2018;46:e649-55.

27 Lynch R, Laden G, Grout P. Carbon monoxide poisoning: correlation of neurological findings between accident and emergency departments and a hyperbaric unit. Emerg Med J 2001;18:95-8.

28 Weaver LK, Howe S, Hopkins R, et al. Carboxyhemoglobin half-life in carbon monoxide-poisoned patients treated with $100 \%$ oxygen at atmospheric pressure. Chest 2000;117:801-8.

29 Hampson NB, Hauff NM. Risk factors for short-term mortality from carbon monoxide poisoning treated with hyperbaric oxygen. Crit Care Med 2008;36:2523-7.

$30 \mathrm{Cha} \mathrm{YS}, \mathrm{Cha} \mathrm{KC}, \mathrm{Kim} \mathrm{OH}$, et al. Features and predictors of myocardial injury in carbon monoxide poisoned patients. Emerg Med J 2014;31:210-5

31 Henry TD, Lesser JR, Satran D. Myocardial fibrosis from severe carbon monoxide poisoning detected by cardiac magnetic resonance imaging. Circulation 2008;118:792.

32 Satran D, Henry CR, Adkinson C, et al. Cardiovascular manifestations of moderate to severe carbon monoxide poisoning. J Am Coll Cardiol 2005;45:1513-6.

33 Henry CR, Satran D, Lindgren B, et al. Myocardial injury and longterm mortality following moderate to severe carbon monoxide poisoning. JAMA 2006;295:398-402.

34 Lippi G, Rastelli G, Meschi T, et al. Pathophysiology, clinics, diagnosis and treatment of heart involvement in carbon monoxide poisoning. Clin Biochem 2012;45:1278-85

35 Kalay N, Ozdogru I, Cetinkaya Y, et al. Cardiovascular effects of carbon monoxide poisoning. Am J Cardiol 2007;99:322-4.

36 Weaver LK, Valentine KJ, Hopkins RO. Carbon monoxide poisoning: risk factors for cognitive sequelae and the role of hyperbaric oxygen. Am J Respir Crit Care Med 2007;176:491-7.

37 Huang $\mathrm{C}-\mathrm{C}$, Ho C-H, Chen $\mathrm{Y}-\mathrm{C}$, et al. Hyperbaric oxygen therapy is associated with lower short- and long-term mortality in patients with carbon monoxide poisoning. Chest 2017;152:943-53.

38 Huang $\mathrm{C}-\mathrm{C}$, Ho $\mathrm{C}-\mathrm{H}$, Chen $\mathrm{Y}-\mathrm{C}$, et al. Impact of hyperbaric oxygen therapy on subsequent neurological sequelae following carbon monoxide poisoning. J Clin Med 2018;7.

39 Lo C-P, Chen S-Y, Chou M-C, et al. Diffusion-tensor MR imaging for evaluation of the efficacy of hyperbaric oxygen therapy in patients with delayed neuropsychiatric syndrome caused by carbon monoxide inhalation. Eur J Neurol 2007;14:777-82. 